\title{
Localised genital Norwegian scabies in an AIDS patient
}

\author{
A G Perna, K Bell, T Rosen
}

Sex Transm Infect 2004;80:72-73. doi: 10.1136/sti.2003.002048

Objectives: We present a case of an AIDS patient with Norwegian scabies manifest by a single, crusted plaque localised to the glans penis.

Methods: A 45 year old man with AIDS presented to our clinic complaining of a red papular pruritic rash on his abdomen and anterior thighs and a single, thick, crusted, non-pruritic lesion on the penis. He had been treated with lindane topically prior to the development of the penile lesion without resolution of the pruritus or red papular lesions. A mineral oil preparation was obtained from the hyperkeratotic penile lesion and revealed numerous mite eggs and faeces. Results: The diagnosis of localised, genital Norwegian scabies was made. The patient was treated with ivermectin $200 \mu \mathrm{g} / \mathrm{kg}$ per dose taken as two doses, 14 days apart, with complete resolution of both pruritus and skin lesions.

Conclusions: This patient is the first known report of Norwegian scabies localised as a single lesion on the penis. He was successfully treated with oral ivermectin monotherapy.

$\mathrm{N}$ orwegian scabies, or crusted scabies, is a severe form of infestation by Sarcoptes scabiei seen in immunocompromised patients. Patients characteristically develop extensive thick, hyperkeratotic lesions in a more or less generalised fashion with notable involvement of the extremities-back, face, scalp, and periungual region. ${ }^{1-3}$ Although the clinical appearance can vary dramatically to include papular and psoriasiform eruptions, lesions are usually not localised. ${ }^{2}$ To our knowledge, no case of Norwegian scabies localised solely to the genitalia has been previously reported.

\section{CASE REPORT}

A 45 year old Hispanic HIV positive man with an absolute CD4 count of 7 cells $\times 10^{6} / 1$ presented to our clinic in April 2002 with a several months' history of a pruritic red papular eruption on the abdomen and anterior thighs. The patient had been prescribed lindane topically in two overnight treatments separated by 7 days. Though he used the lindane extensively (over his entire body surface, including the genitalia) and even more frequently (every other night), the infection did not respond. His wife and adult daughter, who lived with him, both reported pruritus without skin lesions. The patient coincidentally noticed an enlarging, non-pruritic, thick, crusted papule on the shaft of his penis that had been growing for roughly 2 months and was $1.6 \mathrm{~cm}$ in diameter on the day of presentation (fig 1). A mineral oil preparation from the crusted penile lesion revealed numerous typical mite eggs and scybala, confirming the clinical diagnosis of Norwegian (crusted) scabies. The patient had no acral skin changes and no other areas of thick crusting.

The patient was treated with two doses of oral ivermectin at $200 \mu \mathrm{g} / \mathrm{kg} /$ dose separated by 14 days. The patient received no further topical therapy, but his wife and daughter were given permethrin topical therapy to use overnight in two applications separated by 7 days. The patient returned after 21 days with complete resolution of his skin lesions and pruritus.

\section{DISCUSSION}

Norwegian (crusted) scabies most commonly develops in the population of HIV infected patients; however, individuals with other severe immunosuppressive diseases or those who use systemic or topical immunosuppressants are similarly susceptible. ${ }^{1}$ This is probably because of the inability of the immune system to combat the mites, thereby facilitating an overwhelming reproduction.

There is a wide range of presentations of Norwegian scabies in AIDS patients. Lesions range from thick, crusted plaques to red papules to psoriasiform plaques to hyperkeratotic yellow coloured papules resembling Darier's disease. ${ }^{2}$ Burrows are characteristic in typical scabies, but may be absent in scabies among AIDS patients. ${ }^{12}$ Pruritus is absent or decreased with Norwegian scabies compared to the intense pruritus characteristic of ordinary scabies. ${ }^{12}$ The lesions in Norwegian scabies are classically distributed on the extremities, but are frequently found on the back, face, scalp, and around the nailfolds. ${ }^{1-3}$ Our patient's presentation of pruritic red papules on the abdomen and thighs without burrows was not unusual for an AIDS patient with Sarcoptes scabiei infestation, but the presence of a single thickly hyperkeratotic plaque localised to the glans penis has not yet been reported.

Crusted scabies is particularly difficult to treat because traditional topical therapies do not penetrate sufficiently to eliminate the infection. Attention has turned towards the use of oral ivermectin as a highly effective alternative treatment, ${ }^{3-10}$ but there remains no definitive consensus on the optimal dosing regimen (including the total number of doses and interval between them) and on the need for concomitant topical therapy. ${ }^{11}{ }^{12}$ The majority of reports suggest the use of two doses $(200 \mu \mathrm{g} / \mathrm{kg}$ each) given 2 weeks apart. Our patient's pruritus and all cutaneous lesions resolved completely following administration of this exact regimen and without the necessity for adjunctive topical therapy.

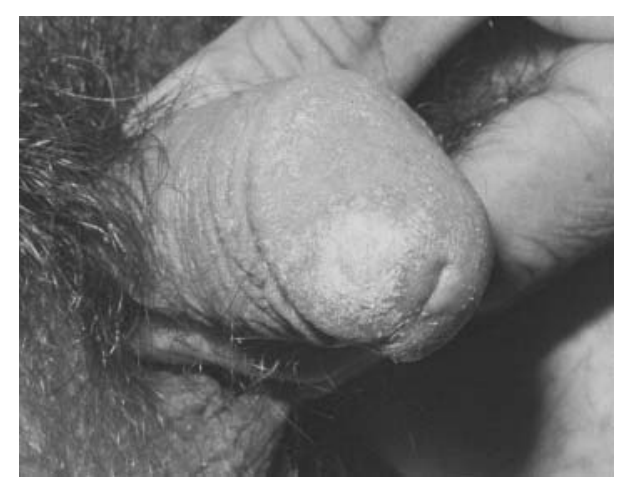

Figure 1 A single crusted penile lesion representing Norwegian scabies in AIDS patient. 


\section{CONTRIBUTORS}

All three authors directly contributed to the care of this patient and writing and editing of this manuscript.

\section{Authors' affiliations}

A G Perna, K Bell, T Rosen, Department of Dermatology, Baylor College of Medicine, Houston, TX, USA

Correspondence to: Theodore Rosen, MD, Department of Dermatology, Baylor College of Medicine, One Baylor Plaza, Houston, TX 77030,

USA; tedrosenmd@aol.com

Accepted for publication 12 August 2003

\section{REFERENCES}

1 Orkin M. Scabies in AIDS. Semin Dermatol 1993;12:9-14.

2 Schlesinger I, Oelrich DM, Tyring SK. Crusted (Norwegian) scabies in patients with AIDS: the range of clinical presentations. South Med J 1994;87:352-6.
3 Cestari SCP, Petri V Rotta $O$, et al Oral treatment of crusted scabies with ivermectin: report of two cases. Pediatr Derm 2000;17:410-4.

4 Marliere V, Roul S, Labreze C, et al. Crusted (Norwegian) scabies induced by use of topical corticosteroids and treated successfully with ivermectin. J Pediatr 1999; 135:122-4.

5 Camassa F, Fania M, Ditano G, et al. Neonatal scabies. Cutis 1995;56:210-2.

6 Meinking TL, Taplin D, Herminda JL, et al. The treatment of scabies with ivermectin. N Engl J Med 1995;333:26-30.

7 Corbett EL, Crossley I, Holton J, et al. Crusted (Norwegian) scabies in a specialist HIV unit: successful use of ivermectin and failure to prevent nosocomial transmission. Genitourin Med 1996;72:115-7.

8 Patel A, Hogan P, Walder B. Crusted scabies in two immunocompromised children: successful treatment with oral ivermectin. Australas J Dermatol 1999:40:37-40.

9 Pellizer G, Betto P, Manfrin V, et al. Ivermectin treatment of AIDS-related, crusted scabies. Eur J Dermatol 1996;6:396.

10 Guggisberg D, de Viragh PA, Constantin C, et al. Norwegian scabies in a patient with acquired immunodeficiency syndrome. Dermatology 1998; 197:306-8

11 Burkhart CG, Burkhart CN. Optimal treatment for scabies remains undetermined. J Am Acad Derm 2001;45:637-8.

12 Haas $\mathrm{N}$, Henz BM, Ohlendorf $\mathrm{D}$. Is a single oral dose of ivermectin sufficient in crusted scabies? Int J Dermatol 2001;40:599-600. 